
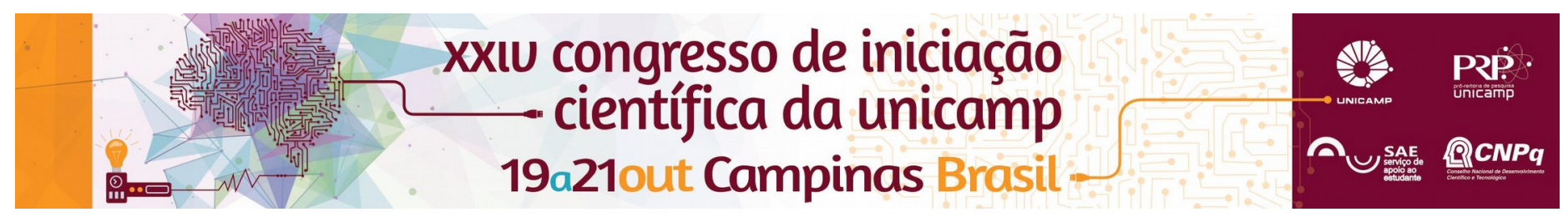

\title{
Um método de deconvolução bayesiana para análise de dados
}

\section{Fernanda Cristina Rufino*, José Augusto Chinellato.}

\section{Resumo}

Este trabalho continua o projeto de iniciação científica $2014 / 2015$ no qual foi estudado um método de deconvolução bayesiana[1] a ser aplicado em análise de dados experimentais de chuveiros atmosféricos extensos de altíssimas energias. Neste trabalho, será aplicado o método em simulações realizadas através dos softwares CORSIKA e Offline que reconstruíram chuveiros atmosféricos extensos detectados pelos detectores de superfície (SD) do Observatório Pierre Auger. O método foi desenvolvido a partir dos trabalhos de Bhat et al[2] e da tese de doutorado de E. Perassa.

\section{Palavras-chave:}

Raios cósmicos, física de partículas elementares, análise de dados.

\section{Introdução}

É muito comum no estudo de física de partículas de alta energia, astrofísica e astronomia nos depararmos com situações extremas de números reduzidos de dados como no caso estudado nesse trabalho, em que os dados dos múons e dos elétrons adquiridos nos detectores SD estão emaranhados. Neste caso, o método de deconvolução bayesiana torna-se muito vantajoso quando comparado a outros métodos.

As simulações dos chuveiros atmosféricos detectados no Observatório Pierre Auger são realizadas através dos softwares CORSIKA e Offline. Os dados gerados correspondem às detecções dos 1660 módulos Cherenkov dos chuveiros com energias acima de 1018 eV. Os Chuveiros Atmosféricos Extensos (CAEs) são iniciados por raios cósmicos que ao incidir na atmosfera da Terra, dão início a produção de partículas formando uma cascata que cresce em número de partículas até um ponto crítico, quando a partícula não possui energia suficiente para gerar outras e depois decresce. A partir desses chuveiros é possível detectar, de maneira indireta, a partícula primária que incidiu na atmosfera[3].

\section{Resultados e Discussão}

Para a realização do processo de deconvolução, foi implementado um programa em $\mathrm{C}++$, compilado e executo pelo framework ROOT. Para tal processo, é necessário três conjuntos de dados, sendo eles: os histogramas do perfil dos múons, dos elétrons e os dados do SD. Na figura 1.a é possível observar o histograma dos múons, é visível que seu perfil segue uma distribuição gama e seu pico é maior e deslocado em relação ao pico do histograma dos elétrons, apresentado na figura 1.b, que segue uma função seno.
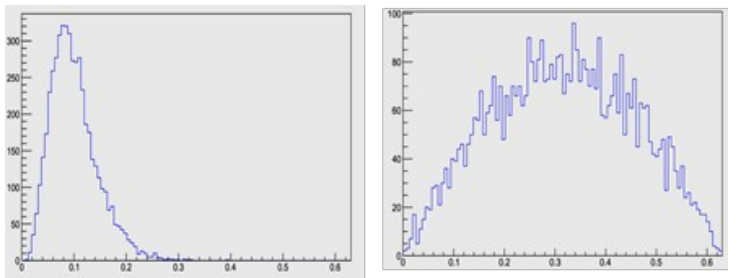

Figura 1. Histogramas dos perfis das componentes a) muônica e b) eletromagnética.
Na figura 2.a é apresentado um histograma semelhante aos que são obtidos na simulação dos dados obtidos pelo SD. O perfil do histograma é a convolução dos dois outros histogramas da figura 1. $\mathrm{Na}$ figura 2.b, temos resultado do processo de deconvolução pelo método bayesiano. A interpretação de $2 . b$ indica que no histograma da simulação do SD existe uma contribuição de $38 \%$ de elétrons e portanto $72 \%$ de múons.
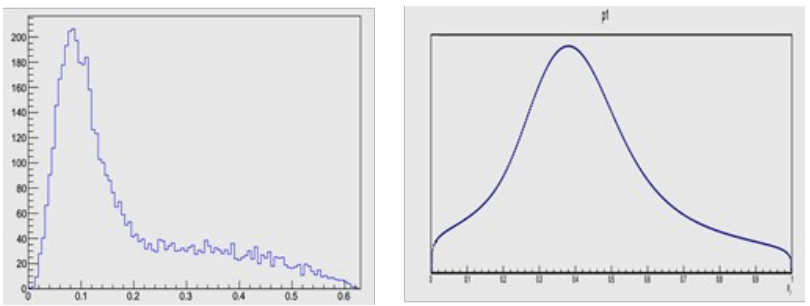

Figura 2. a) histograma da convolução das componentes muônica e eletromagnética. b) peso relativo da componente eletromagnética.

As curvas não estão normalizadas, uma vez que as variáveis a serem encontradas são as contribuições relativas de cada componente.

\section{Conclusão}

Através desse trabalho é possível desenvolver um método eficiente para a deconvolução das componentes muónica e eletromagnética do espectro do sinal detectado nos tanques do Observatório Auger. Os resultados que estão sendo obtidos são muito bons, uma vez que, a contribuição de uma das componentes obtida pela aplicação do método retorna a original, com boa precisão. Para esse segundo semestre, um dos focos de estudo será na largura da distribuição da figura 2.b.

\section{Agradecimentos}

Agraço do programa BAEF/SAE pelo apoio financeiro.

\footnotetext{
Sivia, D.S., Skilling, J., Data analysis: a Bayesian tutorial, Oxford science publications. Oxford University Press (2006).

${ }^{2}$ Bhat P.C., Prosper H.B., Snyder S. Bayesian analysis of multisource data "Phys. Lett. , 407 (1997) 73-78.

Theodoro, V. M.. Contribuição para os métodos de identificação das componentes eletromagnética e muônica de chuveiros atmosféricos extensos no Observatório Pierre Auger, Tese de mestrado, Universidade Estadual de Campinas (UNICAMP), 2011.
} 